\title{
Interleukin-18 and interleukin-18 receptor- $\alpha$ expression in allergic asthma
}

\section{To the Editors:}

The inflammatory process in allergic asthma is initiated by Thelper (Th) type-2 cells, which produce a repertoire of cytokines, including interleukin (IL)-4, IL-5, IL-9 and IL-13, which are necessary for immunoglobulin (Ig)E production, airway eosinophilia and goblet cell hyperplasia [1]. IL-18 is another pro-inflammatory cytokine, initially described as interferon (IFN)- $\gamma$-inducing factor [2]. IL-18 can act as a cofactor for Th2 cell development and IgE production [3]. Recently, an IL-18 gene polymorphism was reported to be associated with asthma severity and higher serum IL-18 levels: the rs5744247 variant, which has higher transcriptional activity than the wildtype allele [4]. In addition, the IL-18 receptor (IL$18 \mathrm{R}$ ) gene (on $2 \mathrm{q} 21$ ) has been identified as a candidate gene associated with increased susceptibility to asthma in children [5], and polymorphisms of the gene have been associated with allergic asthma and airway hyperresponsiveness (AHR) [6]. We have evaluated serum levels of IL-18 and the expression of IL-18R $\alpha$, as well as other Th2-associated cytokines, in stable allergic asthmatic subjects, compared with allergic nonasthmatic subjects and healthy controls.

We studied 36 subjects, which included 15 allergic asthmatic subjects, 11 nonasthmatic allergic subjects and 10 healthy controls (table 1). All subjects underwent a methacholine inhalation challenge [7] and had skin-prick tests to a panel of 16 environmental allergens. Total IgE, and serum IL-18, IL-4, IL10, IL-12, IL-13 and IFN- $\gamma$ were measured using commercially available ELISA kits (Medical and Biological Laboratories Co., Nagoya, Japan; R\&D Systems, Minneapolis, MN, USA; DRG International Inc., Mountainside, NJ, USA). The allergic subjects were studied outside of their allergen season. Fibreoptic bronchoscopy and airway biopsies were taken from four allergic asthma subjects. Airway biopsies were fixed with $10 \%$ formalin and embedded in paraffin wax. Immunohistochemical analysis was performed as previously reported [8].

Peripheral blood mononuclear cells (PBMCs) were isolated from peripheral blood using of Lymphoprep ${ }^{\circledR}$ (Nycomed, Oslo, Norway) density gradient separation. PBMCs were washed in fluorescence-activated cell sorting (FACS) buffer (PBS supplemented with $0.1 \%$ sodium azide and $0.5 \%$ bovine serum albumin) and suspended to a density of $1 \times 10^{6}$ cells in $100 \mu \mathrm{L}$ mouse block ( $5 \%$ mouse serum and $5 \%$ human serum in FACS buffer; Sigma-Aldrich, St Louis, MO, USA), then incubated for $20 \mathrm{~min}$. This was followed by surface staining with phycoerythrin (PE)-conjugated IL-18R $\alpha$ (R\&D Systems), Pacific Blue-conjugated CD45 (eBioscience, San Diego, CA, USA), PE-cyanin7-conjugated CD3, fluorescein isothiocyanateconjugated CD4, allophycocyamin (APC)-conjugated CD56 (BD Pharmingen, San Diego, CA, USA), APC-conjugated CD8 (BD Biosciences, San Jose, CA, USA) or PE-conjugated isotype-matched mouse IgG1 control antibodies (BD Pharmingen) in the dark at $4^{\circ} \mathrm{C}$ for $30 \mathrm{~min}$. Next, the samples were centrifuged at $405 \times g(1,500 \mathrm{rpm})$ for $10 \mathrm{~min}$ at $4^{\circ} \mathrm{C}$. The supernatant was aspirated and the cells were fixed with $350 \mathrm{~mL}$ of $1 \%$ paraformaldehyde. Stained cells were then stored in the dark at $4{ }^{\circ} \mathrm{C}$ until flow-cytometric acquisition $<48 \mathrm{~h}$ after staining.

Cells were acquired with a 15-colour LSR II flow cytometer equipped with three lasers (Becton Dickinson Instrument Systems, Franklin Lakes, NJ, USA) using the FACSDiva software (BD Biosciences). A lymphocyte gate was set up around the lymphocyte cell population on the side scatter (SSC) versus CD45 plot and then transferred to a SSC versus CD3 plot to identify CD3-positive and -negative cell populations. CD3positive cell populations were separated from CD4- and CD8positive cell populations by CD4 versus CD8 plot. CD3 negative cell populations were separated from CD56-positive cells populations by CD56 plot and CD3 plot. The IL-18R $\alpha$-positive cell population in CD3-, CD4-, CD8- and CD56-positive cells was detected using the isotype-matched mouse IgG1 control. Nonparametric tests (Kruskal-Wallis and Mann-Whitney Utests) were used to compare differences between the groups. Statistical significance was considered to be $\mathrm{p}<0.05$.

As expected, the asthmatic subjects had methacholine provocative concentration causing a $20 \%$ decrease in forced expiratory volume in $1 \mathrm{~s}$ (PC20) values that were significantly lower than those of the nonasthmatic allergic subjects and healthy controls $(p<0.01)$. The levels of total $\operatorname{IgE}$ were also significantly higher in nonasthmatic allergic subjects and asthmatics than in healthy controls $(\mathrm{p}<0.05)$ (table 1$)$.

We identified that serum levels of IL-18 were significantly higher in the asthmatic subjects (mean \pm SEM $336.12 \pm 36.95 \mathrm{pg} \cdot \mathrm{mL}^{-1}$ ), when compared with either the nonasthmatic allergic subjects or the healthy controls $\left(218.70 \pm 20.85\right.$ and $213.68 \pm 15.62 \mathrm{pg} \cdot \mathrm{mL}^{-1}$, respectively) $(\mathrm{p}<0.05)$ (fig. 1). By contrast, serum levels of IL-4, IL-10, IL-12, IL-13 and IFN- $\gamma$ were not significantly different between the groups (fig. 1). In the asthmatic subjects, there was a significant correlation between serum IL-18 levels and methacholine PC20 ( $\mathrm{r}=-0.517, \mathrm{p}<0.05)$, and in the entire population, there was a trend towards a significant correlation between serum IL-18 levels and the levels of $\operatorname{IgE}(\mathrm{r}=0.33, \mathrm{p}=0.053)$. There were no significant differences in IL- $18 \mathrm{R} \alpha$ expression on CD3, CD4, CD8 and CD56 cells between the groups.

IL-18 protein was strongly expressed in airway epithelium cells and smooth muscle cells in airway biopsies from allergic asthmatic subjects. IL-18R $\alpha$ was weakly expressed in airway epithelium but not on airway smooth muscle. A representative example is shown in figure 2 and similar changes were seen in biopsies from all four allergic asthmatic subjects.

Higher serum levels of IL-18 have previously been identified in asthmatic subjects [9] when compared with healthy control subjects; that study, however, did not include a control group of allergic, nonasthmatic subjects. Significantly higher serum 


\section{TABLE 1 Subject characteristics}

\begin{tabular}{|c|c|c|c|}
\hline Patients $\mathrm{n}$ & 10 & 11 & 15 \\
\hline Males $\mathrm{n}$ & 3 & 5 & 8 \\
\hline Females $\mathbf{n}$ & 7 & 6 & 7 \\
\hline FEV $1 \%$ pred & $96.1 \pm 2.2$ & $92.2 \pm 4.3$ & $90.9 \pm 3.5$ \\
\hline
\end{tabular}

Data are presented as $\mathrm{n}$, mean \pm SEM or mean (geometric SEM), unless otherwise stated. FEV : forced expiratory volume in 1 s; \% pred: \% predicted; PC20: provocative concentration causing a $20 \%$ decrease in $\mathrm{FEV}_{1}$; Ig: immunoglobulin. ${ }^{*}$ : $p<0.05$ versus nonallergy; ${ }^{* \star}$ : $p<0.01$ versus nonallergy and allergy.

IL-18 levels have also been described in patients with acute severe asthma when compared with healthy subjects [10]. In our study, the allergic, nonasthmatic subjects did not have elevated IL-18 levels when compared with normal controls; this suggests that the increase in circulating IL-18 is specific for asthma.

The demonstration of the correlation of serum IL-18 levels with methacholine PC20 values in asthmatic subjects and the trend for a correlation with serum $\operatorname{IgE}$ in the entire population of subjects studied are also novel observations. The most plausible explanation for the association of IL-18 with increased levels of $\operatorname{IgE}$ and methacholine AHR is that these are indirect effects. Previous studies have shown that IL-18 plays a role in the allergen-induced development of Th2 cells and it is possible that the associated increase in Th2 cytokines, such as IL-4 and IL-13, which are necessary for IgE production and AHR in mice, is responsible.

IL-18 protein was strongly expressed in airway epithelium cells and smooth muscle cells, while IL-18R $\alpha$ was expressed only on airway epithelium. These results suggest that airway structural cells have the ability to produce IL-18 in asthmatics. We have also previously reported that IL-18 protein is strongly expressed in both the bronchiolar and alveolar epithelium in patients with very severe COPD [8]. Unfortunately, we did not have airway biopsies from allergic or normal controls to determine whether the location of the protein and receptor expression was specific for allergic asthma.

We conclude that the pro-inflammatory cytokine IL-18 may play an important role in the pathogenesis of allergic asthma
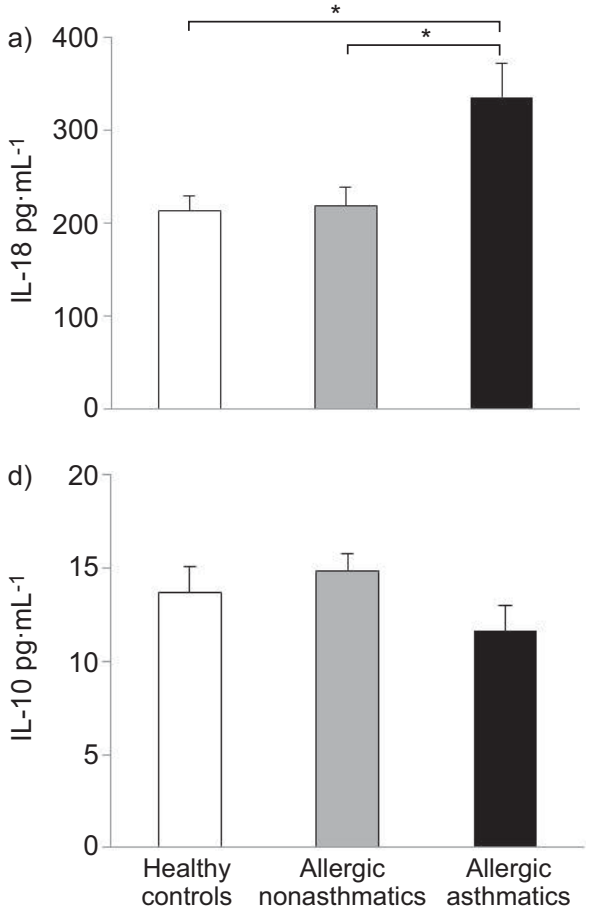
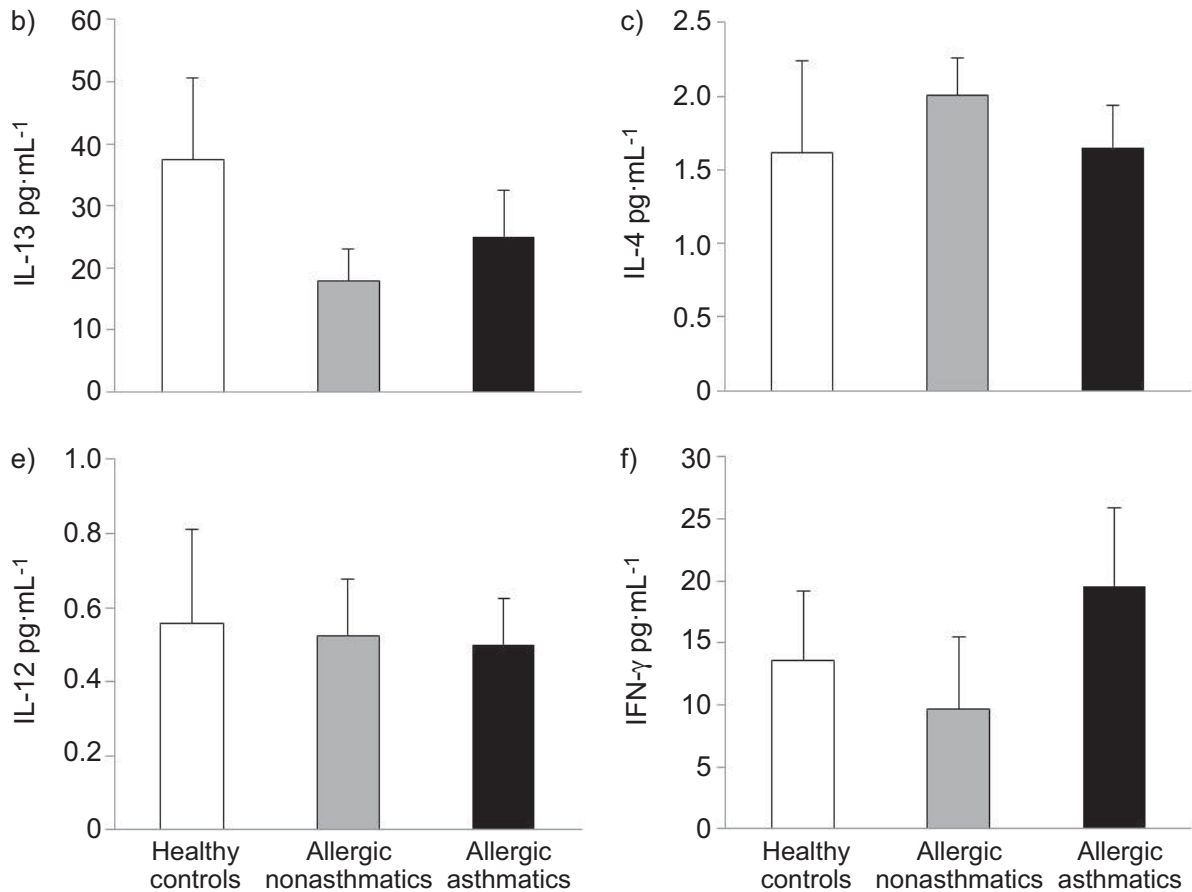

FIGURE 1. Serum levels of a) interleukin (IL)-18, b) IL-13, c) IL-4, d) IL-10, e) IL-12 and interferon (IFN)- $\gamma$ in healthy controls ( $n=10$ ), allergic nonasthmatics ( $n=11$ ) and allergic asthmatics $(n=15)$ subjects. Data are presented as mean \pm SEM. *: $p<0.05$. 

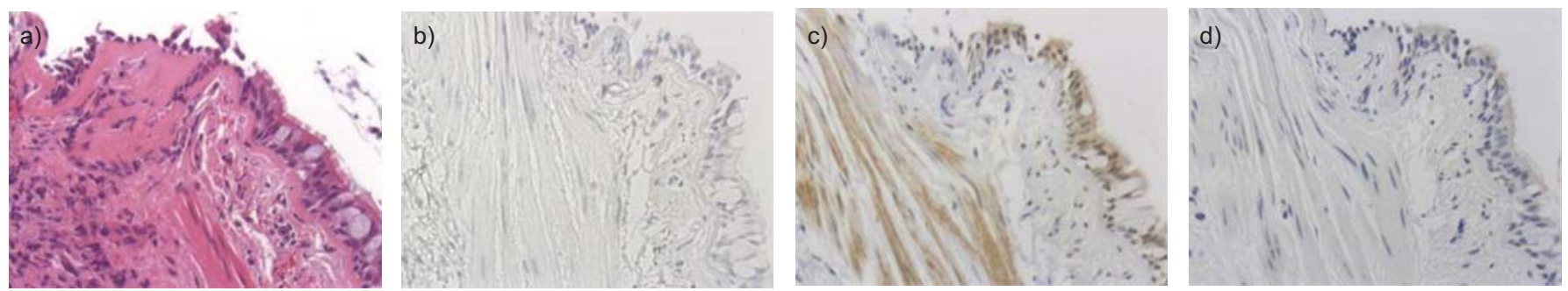

FIGURE 2. Immunostaining of airway biopsy tissue with mouse anti-interleukin (IL)-18 monoclonal antibodies and anti-IL-18R $\alpha$ in an allergic asthma subject (200 $\times$ ) Positive staining for IL-18 is seen in the airway epithelium and airway smooth muscle, while positive staining for IL-18 receptor (IL-18R) $\alpha$ is seen only in the airway epithelium. a) Haematoxylin and eosin; b) negative control; c) IL-18; d) IL-18R $\alpha$.

through its role in the development of IgE and AHR. Further studies to elucidate the importance of IL-18 in allergic asthma would require the availability of humanised anti-IL-18 monoclonal antibodies to block the effects of IL-18.

\section{H. Imaoka*,\#, G.M. Gauvreau*, R.M. Watson*, S.G. Smith*, B. Dua*, A.J. Baatjes*, K. Howie*, T. Hoshino", K.J. Killian*, H. Aizawa ${ }^{\#, \dagger}$ and P.M. O'Byrne*}

*Dept of Medicine, Michael G. DeGroot School of Medicine, Faculty of Health Sciences, McMaster University, Hamilton, ON, Canada, and "Division of Respirology, Neurology and Rheumatology, Dept of Medicine, Kurume University School of Medicine, Kurume, Japan.

Correspondence: P.M. O'Byrne, HSC 3W10, McMaster University, 1200 Main St West, Hamilton, ON, L8N 3Z5, Canada. E-mail: obyrnep@mcmaster.ca

Support Statement: This study was supported by the Canadian Institutes for Health (research grant \#9362).

Statement of Interest: A statement of interest for P.M. O'Byrne can be found at www.erj.ersjournals.com/site/misc/statements. xhtml

Acknowledgements: We thank T. Kawayama, Y. Sakazaki and C. Ohki (all Kurume University, Kurume, Japan) for their technical assistance.

\section{REFERENCES}

1 Cohn L, Elias JA, Chupp GL. Asthma: mechanisms of disease persistence and progression. Annu Rev Immunol 2004; 22: 789-815.

2 Okamura H, Tsutsi $\mathrm{H}$, Komatsu T, et al. Cloning of a new cytokine that induces IFN- $\gamma$ production by T cells. Nature 1995; 378: 88-91.

3 Hoshino T, Yagita H, Ortaldo JR, et al. In vivo administration of IL18 can induce IgE production through Th2 cytokine induction and up-regulation of CD40 ligand (CD154) expression on CD4+ T cells. Eur J Immunol 2000; 30: 1998-2006.

4 Harada M, Obara K, Hirota T, et al. A functional polymorphism in IL-18 is associated with severity of bronchial asthma. Am J Respir Crit Care Med 2009; 180: 1048-1055.

$5 \mathrm{Wu} \mathrm{H}$, Romieu I, Shi M, et al. Evaluation of candidate genes in a genome-wide association study of childhood asthma in Mexicans. J Allergy Clin Immunol 2010; 125: 321-327.

6 Zhu G, Whyte MK, Vestbo J, et al. Interleukin 18 receptor 1 gene polymorphisms are associated with asthma. Eur J Hum Genet 2008; 16: 1083-1090.

7 Juniper EF, Frith PA, Dunnett C, et al. Reproducibility and comparison of responses to inhaled histamine and methacholine. Thorax 1978; 33: 705-710.

8 Imaoka H, Hoshino T, Takei S, et al. Interleukin-18 production and pulmonary function in COPD. Eur Respir J 2008; 31: 287-297.

9 Wong CK, Ho CY, Ko FW, et al. Proinflammatory cytokines (IL-17, IL-6, IL-18 and IL-12) and Th cytokines (IFN- $\gamma$, IL-4, IL-10 and IL-13) in patients with allergic asthma. Clin Exp Immunol 2001; 125: 177-183.

10 Tanaka H, Miyazaki N, Oashi K, et al. IL-18 might reflect disease activity in mild and moderate asthma exacerbation. J Allergy Clin Immunol 2001; 107: 331-336.

DOI: 10.1183/09031936.00033811

\section{Pulmonary malakoplakia: a rare presentation mimicking extensive stage IV lung cancer}

\section{To the Editors:}

Herein, we report a 74-yr-old female who presented with several weeks history of persistent cough productive of mucoid phlegm with specks of haemoptysis. This was associated with fatigue and poor appetite. She also reported a minor episode of nosebleed. She denied any shortness of breath, chest pain, weight loss or any alteration of bowel habit. She complained of some intermittent left-sided pleuritic-type chest pain, which prompted a chest radiograph and urgent referral to the chest clinic thereafter.

Her past medical history included left breast surgery 11 yrs ago for ductal carcinoma in situ, atrial fibrillation, essential 